\title{
Corrigendum
}

\section{Pericellular activation of proMMP-7 (promatrilysin-1) through interaction with CD151}

Takayuki Shiomi, Isao Inoki, Fumio Kataoka, Takashi Ohtsuka, Gakuji Hashimoto, Ryoichi Nemori and Yasunori Okada

Correction to: Laboratory Investigation (2005) 85, 1489-1506. doi:10.1038/labinvest.3700351

Following the publication of the above paper, the author has identified errors in the text on pp 1494, 1495 , and 1501.

On p 1494, Figure 2 legend, line 7, incorrectly states: ${ }^{125}$ I-labeled anti-MMP-7 antibody (125-20H1; lanes 1 and 2) or ${ }^{125}$ I-labeled anti-CD151 antibody (14A2.H1; lanes 3 and 4) ...; the correct data are: ${ }^{125}$ I-labeled antiMMP-7 antibody (125-20H1; lanes 1 and 2) or ${ }^{125} \mathrm{I}-$ labeled anti-CD151 antibody (11G5a; lanes 3 and 4) ...
On p 1495, the paragraph Binding Assay, line 20, incorrectly states: ...CD151 antibody $(10 \mu \mathrm{g} / \mathrm{ml}$; 14A2.H1) or ...; the correct data are: CD151 antibody $(10 \mu \mathrm{g} / \mathrm{ml} ; 11 \mathrm{G} 5 \mathrm{a})$ or ... Also, the paragraph: In situ Zymography Using Crosslinked Carboxymethylated Transferrin (CCM-Tf) Films, line 20, incorrectly states: CD151 antibody (14A2.H1; $25 \mu \mathrm{g} / \mathrm{ml}) \ldots$; the correct data are: CD151 antibody (11G5a; $25 \mu \mathrm{g} / \mathrm{ml}) \ldots$

On p 1501, Figure 7 legend, line 3, incorrectly states: (d), CD151 antibody (14A2.H1); the correct data are: (d), CD151 antibody (11G5a). 